\title{
Fabrication of Mouthguard using Digital Technology
}

Tsukasa Yanagi ${ }^{1}$, Kae Kakura ${ }^{1}$, Takashi Tsuzuki ${ }^{1}$, Kouta Isshi ${ }^{2}$, Yusuke Taniguchi ${ }^{1}$, Takao Hirofuji ${ }^{3}$, Hirofumi Kido ${ }^{1}$ and Masahiro Yoneda $^{3^{*}}$

${ }^{1}$ Department of Oral Rehabilitation, Fukuoka Dental College, Japan

${ }^{2}$ Central Dental Laboratory, Fukuoka Dental College Hospital, Japan

${ }^{3}$ Section of General Dentistry, Department of General Dentistry, Fukuoka Dental College, Japan

\begin{abstract}
Background: Frequent re-fabrication of sports Mouthguards (MGs) due to breakage, loss, etc., causes reimpression taking and model storage problems. Problems with reproduction accuracy also occur because of thickness differences resulting from a variety of effects during fabrication. Therefore, we suspected that an MG with a high level of reproduction accuracy can be fabricated through digital technology to solve these problems. The purpose of this study is to investigate whether high elastic rubber MG can be manufactured using a 3D printer and its accuracy.

Materials and Methods: In this study, the same ready-made plaster model was used as the master model. We used a dental scanner to scan a plaster model, and obtained an STL data of the plaster model. Then, we used software to design an MG which has $2.5 \mathrm{~mm}$ thickness onto the STL data, and fabricated high-elastic silicone rubber MGs (Digital-MGs) using a 3D printer. We made Conventional Mouthguards (CMGs) which were made from $4 \mathrm{~mm}$ thickness EVA sheet as controls. We measured the thickness of the left and right medial-tooth labial side and occlusal surface, first molar buccal side, and occlusal surface, totaling eight places. Each thickness was expressed as mean \pm standard deviation (mean $\pm \mathrm{SD}$ ) and statistical analysis carried out in each group.

Results: The result of measurement was $2.49 \pm 0.22 \mathrm{~mm}$ in CMGs group, $2.51 \pm 0.04 \mathrm{~mm}$ in Digital-MG group. We found area-specific significant differences in the CMGs group, but there was no difference in the Digital-MG group. Digital-MGs were shaped as designed.

Discussion and Conclusion: Due to the problem of model storage and re-impression, application of digital technology such as optical impression and 3D printer to MG fabrication is considered to be useful, and it seems that there is no problem with fabrication accuracy. We believe this will enable the fabrication of MGs with high reproducibility and lead to greater accuracy in MG research.
\end{abstract}

Keywords: Scanner; 3D printer; Sports mouthguard; Reproducibility

\section{Introduction}

The importance of MG use in athletics has recently been realized, and MGs are now mandated in more and more sports. Although disadvantages such as impaired pronunciation and more difficulty breathing have been reported with MG use [1-3], proper MG design can overcome these problems $[4,5]$. Various reports have also been published that extol the usefulness of MGs in preventing trauma [6-9].

There are two types of MGs:

i.) Those that can be self-fabricated using a ready-made product

ii.) Those that are prepared by a dentist, which are called Custom Mouthguards (CMGs)

Takeda, et al. [9] states that only proper MGs have a traumapreventing effect and that conversely, inadequate occlusion adversely affects the viscerocranium. Maeda, et al. [10] further indicates that pronunciation and breathing problems are minimized by wearing a properly fitted MG, and therefore recommend the use of CMG. To make a CMG, usually an impression is taken using an alginate impression material, and after a working model is fabricated, an MG EVA sheet is heated, compressed, and molded. Then an actually useable form is achieved by occlusal registration and adjustment of the MG occlusal surface using opposing teeth-occlusal surface data.

Users of CMGs also include children, however, so care must be taken to avoid vomiting in children unfamiliar with impression taking. In addition, re-fabrication to accommodate growth is necessary for children, and even in adults, periodic re-fabrication is desirable because MG damage and deformation [11] occur with use. Consequently, impression taking and fabrication of a working model must inevitably increase in number. In the case of adults, problems can be avoided by storing a working model, but then the storage space for the models becomes necessary.

Problems also occur in the fabrication process. In the conventional fabrication method of hot-pressure molding of a sheet, the thickness is difficult to control in the anterior area, molar area, etc., and differences in thickness can also arise depending on the original thickness [12] and color [13] of the sheet. If a thickness difference is present, the location of occlusal support changes and affects the position of the mandible, which has also been noted as a problem [14].

We decided to explore digital technology to solve these problems. Various types of digital technology are already used in dentistry [15]. Optical impression taking and CAD/CAM technology has been applied in prosthesis fabrication, and CAD/CAM is already covered by insurance. There have also been attempts to create surgical assistance devices using CAD/CAM [16,17]. 3D printers have also been used clinically to enable fabrication of surgical guides for implants and mandible models for reference during oral surgery. Optical impression taking is effective for patients who have a gag reflex without the risk

${ }^{*}$ Corresponding author: Masahiro Yoneda, Section of General Dentistry, Department of General Dentistry, Fukuoka Dental College, Tamara, Sawara-ku, Fukuoka, Japan, Tel: 81-92-801-0411; Fax: 81-92-801-4909; E-mail: yoneda@college.fdcnet.ac.jp

Received January 22, 2019; Accepted January 31, 2019; Published February 04, 2019

Citation: Yanagi T, Kakura K, Tsuzuki T, Isshi K, Taniguchi Y, et al. (2019) Fabrication of Mouthguard using Digital Technology. Dentistry 9: 531. doi:10.4172/21611122.1000531

Copyright: ( 2019 Yanagi T, et al. This is an open-access article distributed under the terms of the Creative Commons Attribution License, which permits unrestricted use, distribution, and reproduction in any medium, provided the original author and source are credited. 
Citation: Yanagi T, Kakura K, Tsuzuki T, Isshi K, Taniguchi Y, et al. (2019) Fabrication of Mouthguard using Digital Technology. Dentistry 9: 531. doi:10.4172/2161-1122.1000531

of accidental swallowing or aspiration of the impression material, and it places a little burden on the patient. The use of CAD/CAM and 3D printing makes thickness easier to control and enables the fabrication of a reproducible sculpted object. Therefore, we thought digital technology would enable the fabrication of a risk-reducing, easily adjustable Digital-MG. Moreover, because conventional CMGs are made from a soft material such as EVA, we thought that a 3D printer, which enables the $3 \mathrm{D}$ printing of soft materials, is more suitable than CAD/CAM, which creates a prosthetic by carving out a block, and we planned this study on that basis. Therefore, the purpose of this study was to use digital technology to make a Digital-MG prototype.

\section{Materials and Methods}

\section{Digital-MG fabrication}

We took an optical impression using a dental scanner (KaVo ARCTICA Auto Scan ${ }^{\oplus}$ KaVo Dental Systems) with an existing plaster model as the master model. The model data was stored as STL data (Figure 1), and the MG shape and periphery were designed with organic 3D engineering software (Geomagic Freeform Plus ${ }^{\oplus}$, 3D Systems, Inc.) using the model data to create a $2.5 \mathrm{~mm}$ thick MG (Figures 2 and 3).

An MG experimental group ( $n=3)$ of high elastic silicone rubber was sculpted with a high-precision 3D printer (AGILISTA, Keyence Corp.) using the STL data from the MG that had been designed. A control group of conventional MGs (CMGs, $n=3$ ) was fabricated by the following conventional method (Figures 4 and 5).

An EVA sheet (CAPTURE SHEET, thickness $4 \mathrm{~mm}$ for a mouthguard, Shofu, Inc.) was heated in a vacuum forming unit (Erkoform 3D ${ }^{\circ}$, Erkodent Erich Kopp $\mathrm{GmbH}$ ) with the existing model, and then compressed onto the model. The sheet was then trimmed to fabricate the CMGs (Figures 6 and 7).

\section{Digital-MG and CMG comparison}

The thicknesses of the fabricated MGs were measured 3 times each on the facial surfaces $(11 \mathrm{~B}, 21 \mathrm{~B})$ and occlusal surfaces $(11 \mathrm{O}, 21 \mathrm{O})$ of the left and right central incisors, and on the buccal surfaces (16B, 26B) and occlusal surfaces $(16 \mathrm{O}, 26 \mathrm{O})$ of the left and right first molars using a measuring device and calipers (YDM Corp.)

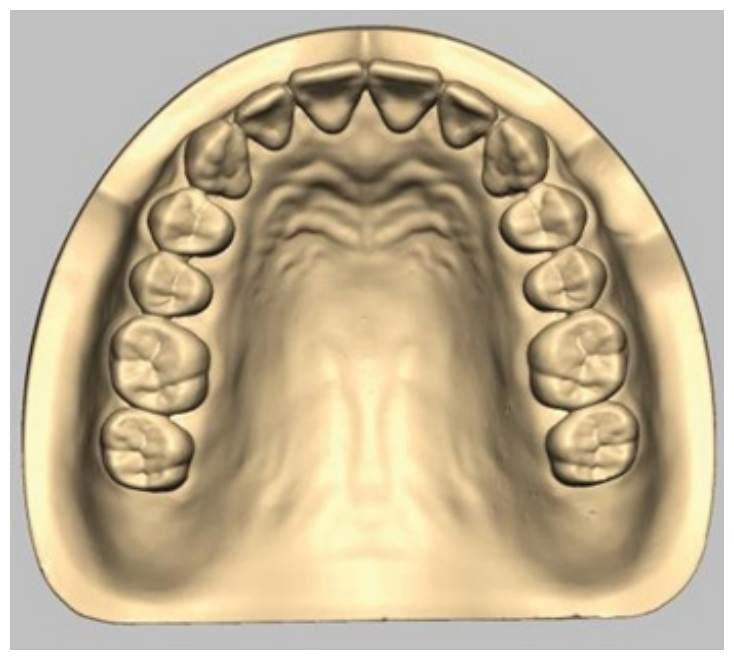

Figure 1: STL data of the plaster model.

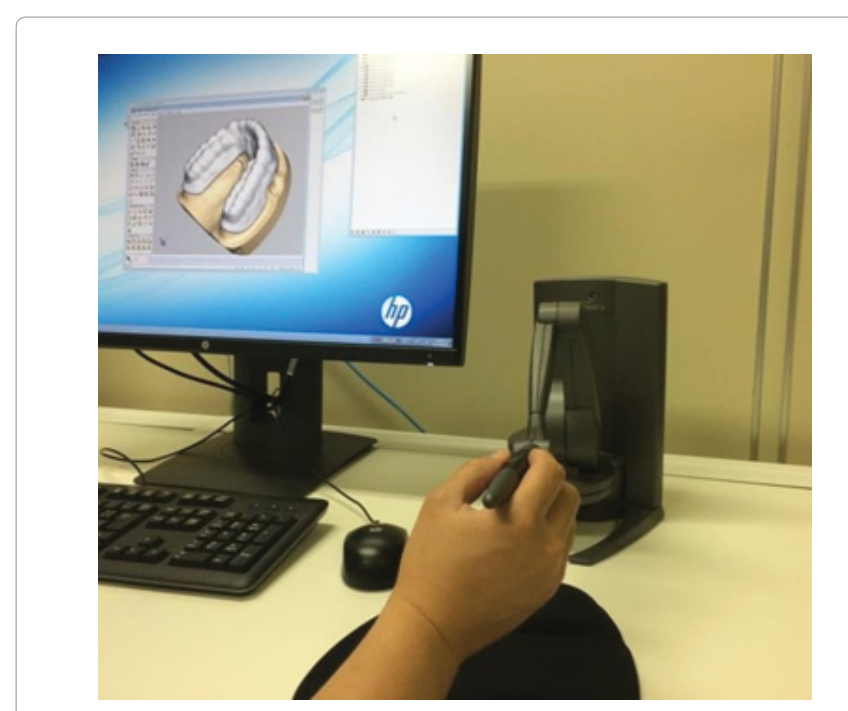

Figure 2: Design of MG with organic shape 3D modeling CAD software.

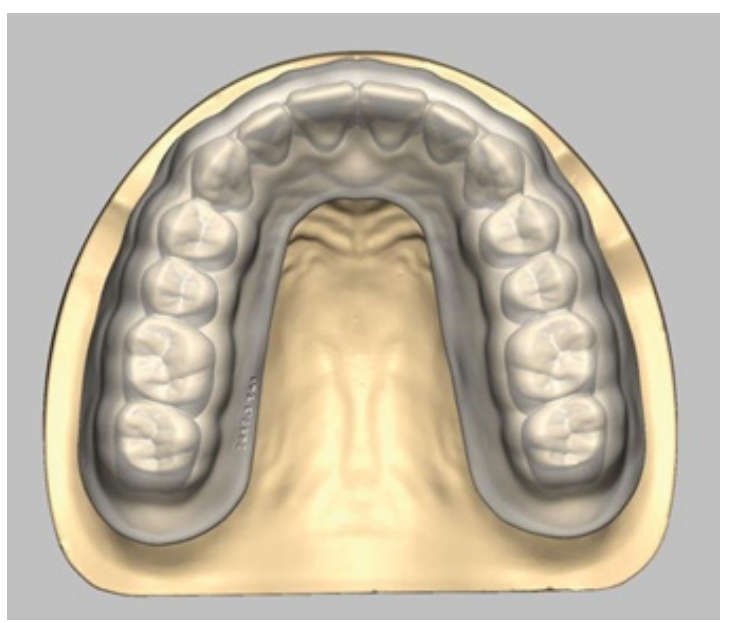

Figure 3: Completed Digital-MG designs.

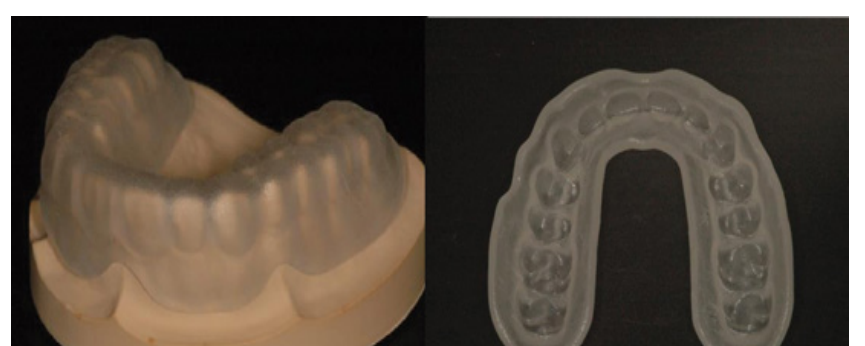

Figure 4: Fabricated Digital-MG and inside.

The measured thicknesses of the CMGs and digital-MGs were expressed as mean \pm SD (Table 1).

\section{Statistical analysis}

The site-specific values on each MG were analyzed using one-way analysis of variance (ANOVA). Then multiple comparison tests were performed using Holm's test with a level of significance of $\alpha=0.05$. 
Citation: Yanagi T, Kakura K, Tsuzuki T, Isshi K, Taniguchi Y, et al. (2019) Fabrication of Mouthguard using Digital Technology. Dentistry 9: 531. doi:10.4172/2161-1122.1000531

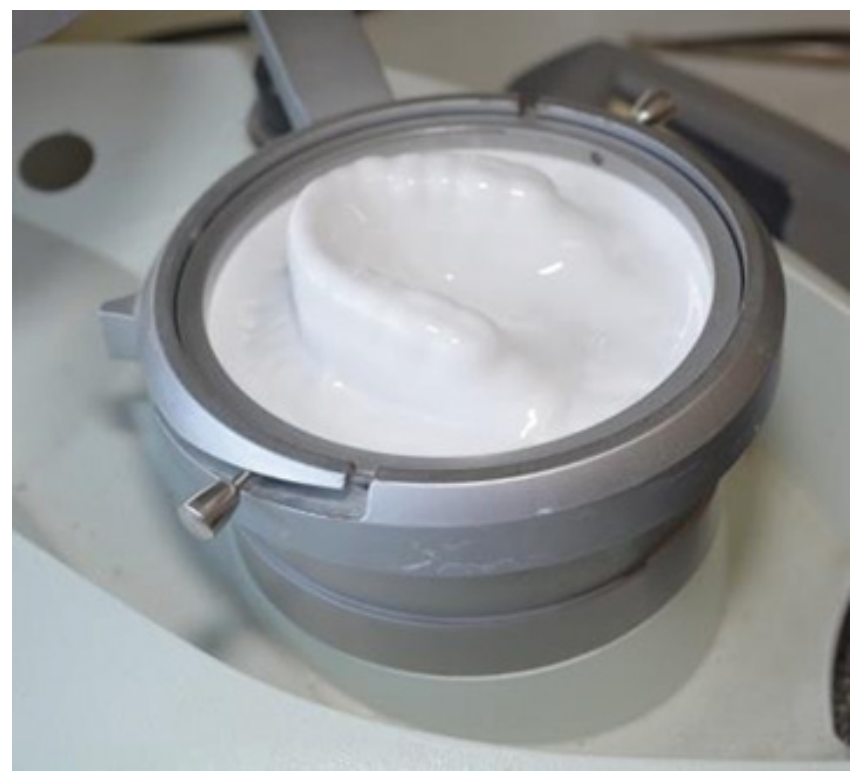

Figure 5: Heating and suction of the EVA sheet by the vacuum forming unit.

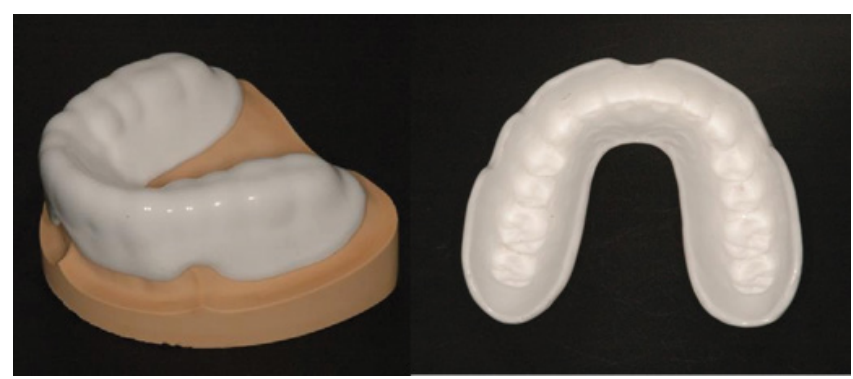

Figure 6: Completed CMG and inside.

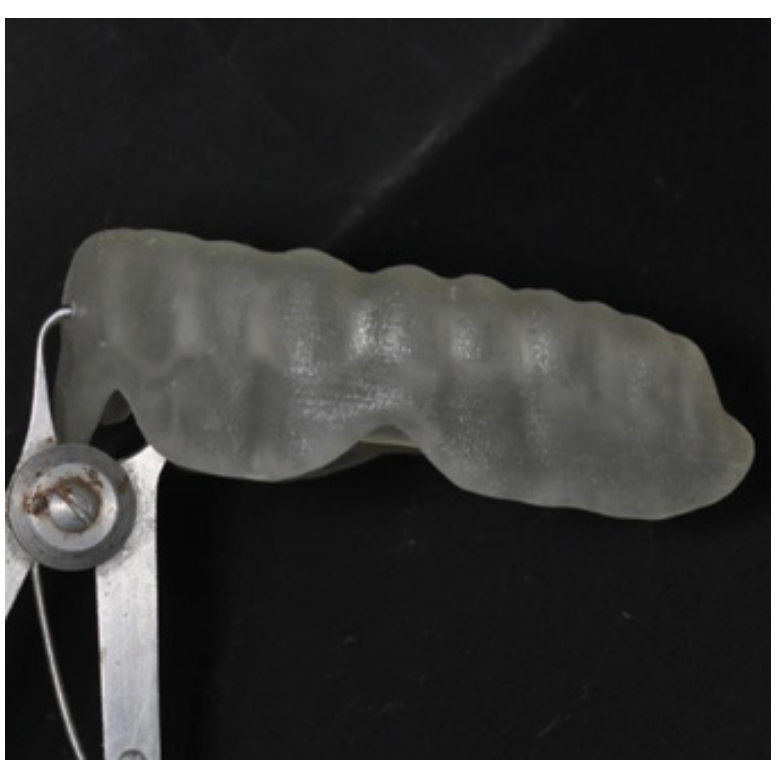

Figure 7: Measurement of thickness with measuring device.

\section{Results}

\section{Digital-MG fabrication}

Both the CMGs and the Digital-MGs conformed well to the master model. The EVA conventional MG material and the high elastic silicone rubber used for the Digital-MGs both have similar physical and handling properties.

\section{Comparison of digital-MGs with CMGs}

Table 1 shows the measurement results for each group. Site-specific measurements in each MG are shown in Table 1.

11: Maxillary right central incisor, 12: Maxillary left central incisor, 16: Maxillary right

first molar, 26: Maxillary left first molar, B: Facial/Buccal side, O: Occlusal side. Measurements were expressed as mean \pm SD.

The site-specific measurements for each type of MGs are shown in the graphs of Figures 8 and 9.

Figure 8 shows the thickness at each location in the fabricated CMG.

11: Maxillary right central incisor, 12: Maxillary left central incisor, 16: Maxillary right first molar, 26: Maxillary left first molar, B: Facial/ Buccal side, O: Occlusal side. The significance level was set to $\alpha=0.05$. Figure 9 shows the thickness at each location in the fabricated DigitalMG.

11: Maxillary right central incisor, 12: Maxillary left central incisor, 16: Maxillary right first molar, 26: Maxillary left first molar, B: Facial/ Buccal side, O: Occlusal side. The significance level was set to $\alpha=0.05$.

The average measurement was $2.49 \pm 0.22 \mathrm{~mm}$ in CMGs group, $2.51 \pm 0.04 \mathrm{~mm}$ in Digital-MG group. The comparison of site-specific thickness showed statistically significant differences in the CMGs

\begin{tabular}{|c|c|c|c|c|c|c|c|c|}
\hline & 11B & 110 & 16B & 160 & 21B & 210 & 26B & 260 \\
\hline CMD & $2.43 \pm$ & $2.77 \pm$ & $2.67 \pm$ & $2.43 \pm$ & $2.27 \pm$ & $2.27 \pm$ & $2.63 \pm$ & $2.43 \pm$ \\
& 0.06 & 0.12 & 0.23 & 0.23 & 0.06 & 0.15 & 0.12 & 0.12 \\
\hline $\begin{array}{c}\text { Digital- } \\
\text { MG }\end{array}$ & $2.5 \pm 0$ & $\begin{array}{c}2.53 \pm \\
0.06\end{array}$ & $\begin{array}{c}2.53 \pm \\
0.06\end{array}$ & $\begin{array}{c}2.53 \pm \\
0.06\end{array}$ & $2.5 \pm 0$ & $\begin{array}{c}2.53 \pm \\
0.06\end{array}$ & $2.5 \pm 0$ & $\begin{array}{c}2.47 \pm \\
0.06\end{array}$ \\
\hline
\end{tabular}

Table 1: Site-specific measurements for CMGs and Digital-MGs.

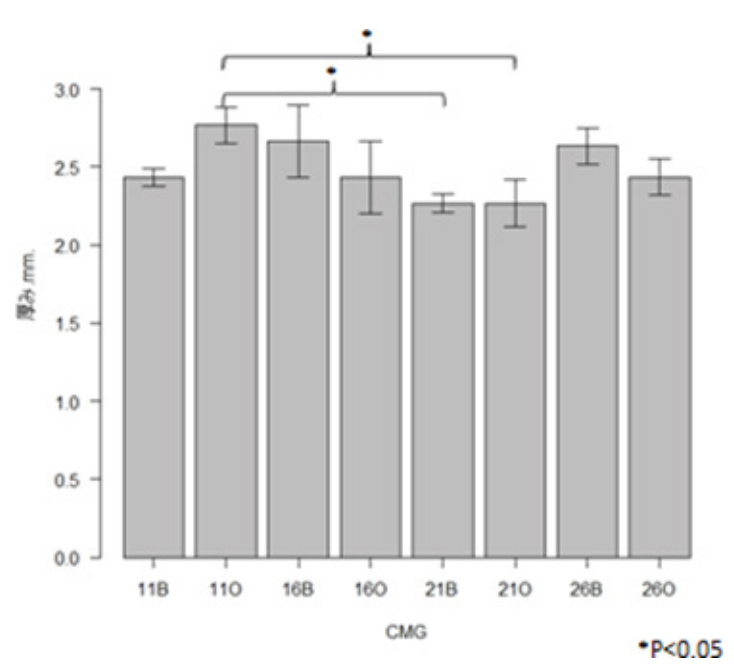

Figure 8: Site specific thickness of the fabricated CMG. 


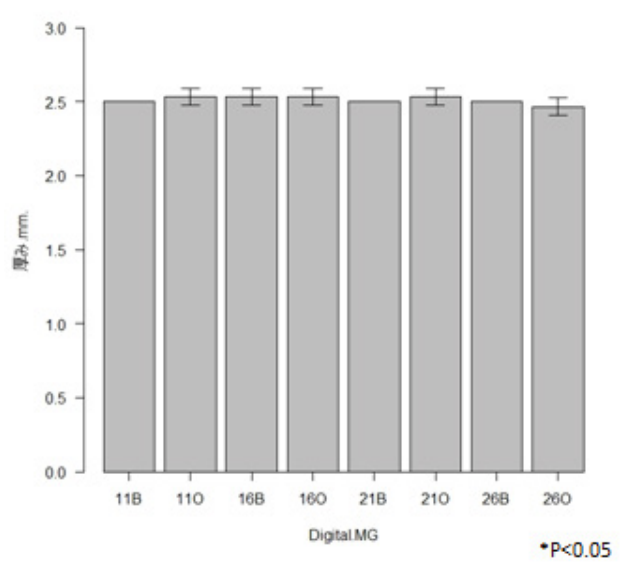

Figure 9: Site specific thickness of the fabricated Digital-MG

group. No left-right or site-specific differences were found in the Digital-MGs, and they had been sculpted as designed in the software.

\section{Discussion}

MGs are considered essential for preventing trauma in contact sports and have actually been mandated in sports such as rugby. Multiple reports have been published on the trauma-preventing effects of CMGs in particular, and many sports dentists have conducted R\&D on fabrication methods and materials to produce even better CMGs. At present the typical CMG production method involves taking an impression with an alginate material to prepare a model, and then heating and compressing an EVA sheet, etc., using a vacuum forming unit. If the patient is growing, however, an impression must be taken for every CMG and this place a heavy burden on the patient. For adults, storing the model is sufficient, but that requires space to store the models. Therefore, we hit upon optical impression taking to solve these problems. Because the oral cavity data can be read by a scanner, there is no risk of accidental swallowing the impression material, and this eases patient distress. The advantage of optical impressions is not only risk reduction. The time and material required for making a plaster model can be reduced, and a model storage space is no longer necessary. Therefore, we believe that optical impression taking will become essential in the future. In addition, a technology that applies this scanned data using CAD/CAM and 3D printers are currently advancing. Differences in thickness occur in CMG fabrication due to various conditions, and this problem is hard to control. With CAD/ CAM and 3D printing, however, milling and molding are performed based on scanned data, so the final product has high precision and excellent reproducibility. Therefore, we thought that a high-quality CMG could be fabricated by applying these digital techniques.

Because the CMGs are made from a flexible material such as an EVA sheet, we thought that sculpting by the $3 \mathrm{D}$ printer is more suitable to MGs than CAD/CAM milling, and chose 3D printing.

Similar attempts have been made in the past. For example, Takamata, et al. [18] first performed a wax up on an actual model to prepare an MG wax pattern, created STL data of the MG by reading the pattern with a scanner, and then fabricated a Digital-MG using an acrylic-like material and a 3D printer. Moreover, Kondo, et al. [19] used an intraoral scanner to scan a model, and then fabricated a Digital-MG using a rubber-like material and a 3D printer. Because no MG studies involving high elastic silicone rubber material have been reported, however, we formed our Digital-MGs using high-elastic silicone rubber for the AGILISTA 3D printer. The sculpted Digital-MGs had elasticity similar to conventional CMGs, and the handling properties were also similar. In CMGs prepared by previous methods it has been difficult to control site-specific thickness and differences in thickness are found depending on the location, but with the Digital-MG it is easy to control the thickness and obtain a shape that matches the design.

Although this also can be noted as one of the merits mentioned previously, using this technology in the future will increase the accuracy of research on the ideal thickness of an MG, the suitable thicknesses of MGs for various sports, and the like. However, the studies by Takamata and Kondo both note the common problem of biological safety, and this also applies to the material that we used. At present our material cannot be used in real patients because it has not been approved for intraoral use, so we cannot ascertain matters such as the actual sensation of the user. However, the digitalization of the MG fabricating process offers many advantages, and we hope that in the future Digital-MGs can be fabricated using current materials, or that approval is obtained for intraoral use of a silicone rubber material that can be used with a $3 \mathrm{D}$ printer.

\section{Conclusion}

We successfully used a 3D printer to fabricate an MG. We believe this will enable the fabrication of MGs with high reproducibility and lead to greater accuracy in MG research.

\section{Conflict of Interest}

No corporate or other conflicts of interest were involved in the preparation of this manuscript.

\section{References}

1. Satoh H, Yonehata $Y$, Maeda $Y$, Sugahara $K$ (2001) Mouthguard design for comfort and wearability. Journal of Sports Dentistry 4: 24-27.

2. Yoshida T, Maeda N, Matono K, Toyama Y (2007) Survey results of compulsory wearing of mouthguards in the 85th japan high school rugby football tournament. Journal of Sports Dentistry 11: 26-32.

3. Cornwell H, Messer LB, Speed H (2003) Use of mouthguards by basketball players in Victoria. Aust Dent Traumatol 19: 193-203.

4. Collares K, Correa MB, Silva IC, Hallal PC, Demarco FF (2013) Effect of wearing mouthguards on the physical performance of soccer and futsal players: a randomized cross-over study. Dent Traumatol 30: 55-59.

5. Gebauer DP, Williamson RA, Wallman KE, Dawson BT (2011) The effect of mouthguard design on respiratory function in athletes. Clin $\mathrm{J}$ Sport Med 21: 95-100.

6. Sumiyoshi S, Nambu T, Honda T, Shimoda T, Miyajima Y, et al. (1996) Efficacy of mouthguards against sports injuries- Finite element method analysis supposing contusion of the chin. Journal of Japanese Society of Oral and Maxillofacial Surgeons 42: 1192-1199.

7. Onyeaso CO, Adegbesan OA (2003) Oro-facial injury and mouthguard usage by athletes in Nigeria. Int Dent J 53: 231-236.

8. Mori T, Matsumoto M, Yasui T, Yoshida K (2001) The effect of the mouthguards on the oral and maxillofacial injury. The Japanese Journal of Safety Education 1: 73-85.

9. Takeda T (2003) The effect of wearing mouthguard and difference of occlusa supportive area on the craniofacial safety. The Journal of the Tokyo Dental College Society 103: 705-713.

10. Maeda Y, Kumamoto D, Yagi K, Ikebe K (2009) Effectiveness and fabrication of mouthguards. Dent Traumatol 25: 556-564.

11. Rossi GD, Lisman $P$, Leyte-Vidal MA (2007) A preliminary report of structura changes to mouthguards during 1 season of high school football. J Athl Train 42: 47-50.

12. Takahashi M, Takahashi F, Morita O (2008) Thickness of mouthguard 
Citation: Yanagi T, Kakura K, Tsuzuki T, Isshi K, Taniguchi Y, et al. (2019) Fabrication of Mouthguard using Digital Technology. Dentistry 9: 531. doi:10.4172/2161-1122.1000531

sheet material after vacuum forming process depending on the thickness of mouthguard sheet. J Jpn Prosthodont Soc 52: 465-472.

13. Takahashi M, Mizuhashi F, Koide K, Mizuhashi R, Morita O (2009) The difference of the thickness of mouthguard sheet material after vacuuum forming process depending on the color of mouthguard sheet. Ann Jpn Prosthodont Soc 1: 396-402.

14. Shirono M, Nagata K, Morita O (2009) Influence of occlusal support of mouthguard on condylar displacement during clenching. Ann Jpn Prosthodont Soc 1: 386-395.

15. Tanaka S, Tachi K, Miyauchi T, Kamimura E, Baba K (2013) Digital dentistry changes the prosthodontics. Dental Medicine Research 33: 215-220.

16. Yamamoto K, Kakura K, Yamamoto K, Yanagi T, Sakai T, et al. (2017) New
CAD/CAM surgical guide with design of an access window in maxillary of sinus floor elevation. Journal of Fukuoka Dental College 42: 63-70.

17. Otawa M, Isshi K, Yasumatsu K, Takayama M, Kakura K, et al. (2017) Clinical application of the surgical guide which applied organic shape modeling three dimensions CAD system. The Journal of the Japan Academy of Digital Dentistry 7: 182-186.

18. Takamata T, Samizo T (2016) Fabrication of sports mouthguard using a 3D Printer. The Journal of the Japanese Society for Dental Materials and Devices 35: 329-332.

19. Kondo H, Fukazawa S (2016) Digital fabrication of mouthguard using optical impression system. The Journal of the Japanese Society for Dental Materials and Devices 35: 333-336. 